\title{
Joint pattern of seasonal hydrological droughts and floods alternation in China's Huai River Basin using the multivariate L-moments
}

\author{
Shaofei Wu $\mathrm{W}^{1,2}$, Xiang Zhang ${ }^{1,3}{ }^{*}$ and DunXian She ${ }^{1,3}$ \\ ${ }^{1}$ State Key Laboratory of Water Resources and Hydropower Engineering Science, Wuhan University, \\ Wuhan 430072, China. \\ ${ }^{2}$ Jiangxi Provincial Key Laboratory of Water Resources and Environment of Poyang Lake, Jiangxi Institute \\ of Water Sciences, Nanchang 330029, China. \\ ${ }^{3}$ Hubei Provincial Collaborative Innovation Center for Water Resources Security, Wuhan 430072, China. \\ *Corresponding author. e-mail: zhangxiang@whu.edu.cn
}

MS received 30 August 2016; revised 18 November 2016; accepted 27 November 2016; published online 7 June 2017

Under the current condition of climate change, droughts and floods occur more frequently, and events in which flooding occurs after a prolonged drought or a drought occurs after an extreme flood may have a more severe impact on natural systems and human lives. This challenges the traditional approach wherein droughts and floods are considered separately, which may largely underestimate the risk of the disasters. In our study, the sudden alternation of droughts and flood events (ADFEs) between adjacent seasons is studied using the multivariate L-moments theory and the bivariate copula functions in the Huai River Basin (HRB) of China with monthly streamflow data at 32 hydrological stations from 1956 to 2012. The dry and wet conditions are characterized by the standardized streamflow index (SSI) at a 3-month time scale. The results show that: (1) The summer streamflow makes the largest contribution to the annual streamflow, followed by the autumn streamflow and spring streamflow. (2) The entire study area can be divided into five homogeneous sub-regions using the multivariate regional homogeneity test. The generalized logistic distribution (GLO) and log-normal distribution (LN3) are acceptable to be the optimal marginal distributions under most conditions, and the Frank copula is more appropriate for spring-summer and summer-autumn SSI series. Continuous flood events dominate at most sites both in spring-summer and summer-autumn (with an average frequency of $13.78 \%$ and $17.06 \%$, respectively), while continuous drought events come second (with an average frequency of $11.27 \%$ and $13.79 \%$, respectively). Moreover, seasonal ADFEs most probably occurred near the mainstream of HRB, and drought and flood events are more likely to occur in summer-autumn than in spring-summer.

Keywords. Alternation of droughts and floods (ADFEs); standardized streamflow index (SSI); regional frequency analysis; multivariate L-moments; copula functions; Huai River Basin (HRB).

\section{Introduction}

A changing climate is intimately linked to changes in the hydrological cycle (Huang et al. 2015). There is a consensus that global warming will change the spatial and temporal patterns of precipitation and thereby result in changes in local dry and wet conditions (Huang et al. 2015; She et al. 2016a). Particularly, changes in hydrological and meteorological extreme events (e.g., droughts and 
floods) may be more significant than changes in the mean conditions (Guhathakurta et al. 2011; Su et al. 2011; Ivett et al. 2013). During the past few decades, droughts and floods have become more intense and frequent, creating widespread concern (Dai et al. 1998; Parry et al. 2007) and causing huge economic losses. For example, the flooding disasters that have largely affected China have resulted in the economic losses of approximately 100 billion Chinese Yuan every year from 2000 to 2010. Moreover, extreme drought events also occurred more frequently and with longer duration and greater severity. For example, the extreme droughts during December 2009 and April 2010 that occurred in five provinces of southwestern China caused decreased crop production and a serious scarcity of drinking water (Ji et al. 2015), and according to the Office of State Flood Control and Drought Relief Headquarters of China, they caused an economic loss of more than 20 billion Chinese Yuan.

The spatio-temporal variability of flood and drought events have attached much attention around the world, as it is of great significance to disaster prevention and regional water resources planning and management (Grimaldi and Serinaldi 2006; Serinaldi et al. 2009; Burke and Brown 2010). For example, Shahid (2008) analyzed the spatial and temporal changes of droughts in western Bangladesh; Santos et al. (2010) studied the droughts in mainland Portugal; Reihan et al. (2012) investigated both the frequency and variation of extreme floods in Baltic States. However, most of the previous studies analyzed droughts and floods separately, and the sudden alternation from drought-to-flood or flood-to-drought event is less studied. In the context of global warming, the prolonged droughts, floods, and alternation of droughts and floods ADFEs between nearby seasons are happening more frequently (Wu et al. 2006; Mu et al. 2014), which will have tremendous negative effects on industrial and agricultural production, as well as surface water environments (Hrdinka et al. 2012; Whitworth et al. 2012), ecosystems (Reichstein et al. 2002; Zeng et al. 2005), economy, food security and human health (Devereux 2007; Bond et al. 2008; Pederson et al. 2009; Leigh et al. 2014). Particularly, the ADFEs, which are characterized by a sudden alternation between floods and droughts, can result in much more serious damage than a separate drought or flood disaster (Wu et al. 2006), always with multi-dimensional and multi-level characteristics of adverse impacts (Huang et al. 2014). The ADFEs can be observed in many regions around the world, especially in the Huai River Basin (HRB) and the Yangtze River Basin of China. Due to climate change and fast urbanization in these two areas, the ADFEs have occurred more frequently in recent years ( $\mathrm{Li}$ and Ye 2015). Hence, separate consideration of droughts and floods cannot fully capture the characteristic changes between droughts and floods and may largely underestimate the hazard risks, which is unbefitting of the hazard management. Therefore, it is crucial to investigate the joint change pattern of continuous dry (wet) conditions and ADFEs between nearby seasons (Huang et al. 2014).

Recently, ADFEs have been investigated at different time scales in studies on the singlesite estimations. Huang et al. (2014) investigated the at-site joint probabilistic characterization of the combination of dry and wet conditions in the Guanzhong Plain of China. However, these previous studies, which were based on single-site estimations of frequency or probability at gauged basins, may not satisfy the requirement on a regional scale. In this way, the regional frequency analysis, which fits distribution and estimates frequency or return period in an entire region, has been proved to be an appropriate approach (She et al. 2014).

Many techniques have been proposed to address the regionalization of hydrological variables $(\mathrm{Mu}$ et al. 2014; She et al. 2014), the most widely used method is the univariate L-moments method proposed by Hosking and Wallis (1993, 1997). This method can only identify a homogeneous region by taking only a single variable into consideration, which is insufficient for fully representing multiple hydrological event phenomena, such as the seasonal continuous droughts, continuous floods and ADFEs that are considered in our study. To overcome this limitation, Chebana and Ouarda (2007) further developed the multivariate case using multivariate L-moments and copula functions, which can construct an extended multivariate regional frequency analysis by identifying a homogeneous region based on all the variables considered jointly (Serfling and Xiao 2007).

In this study, we used multivariable L-moments technique to examine the seasonal drought and flood events between nearby seasons in the HRB from 1956 to 2012. HRB is an important agricultural, industrial and commercial region that encompasses one of the fastest growing economic regions in China. However, because it located in the transition zone between the northern and southern 
climates in China, this region is also very vulnerable to extreme hydro-meteorological events, and has been affected by severe drought and flood hazards since historical times (Ye et al. 2014). In fact, there were 63 extreme floods and 46 extreme droughts recorded in the HRB between 1470 and 2010 (He et al. 2015). Thus, it is important to investigate the changing patterns of droughts and floods in this area to guarantee the security of agricultural production and socio-economic development. The hydrological droughts and floods are represented by the standardized streamflow index (SSI) (VicenteSerrano et al. 2014), which is a widely used index for characterizing the hydrological dry and wet conditions.

The major objectives of this study are: (1) to identify the seasonal drought and flood events in space and time in the HRB based on the SSI; (2) to divide the entire HRB into several homogeneous sub-regions using the multivariate L-moments method, which is appropriate for a multivariate regional frequency analysis; and (3) to investigate the joint probabilities of seasonal continuous hydrological droughts, continuous floods and ADFEs by regional frequency methods via multivariate L-moments method.

This study is organized as follows: the methods are described in section 2, a brief introduction to the study area and data description are presented in section 3; section 4 gives the results, and conclusions and discussions follow in section 5 .

\section{Methodology}

\subsection{Calculation of the seasonal standardized streamflow index (SSI)}

The SSI, principally proposed by Vicente-Serrano et al. (2014), is defined as the unit standard normal deviation associated with the percentile of hydrologic streamflow accumulated over a specific duration. The computation of SSI is similar to the standardized precipitation index (SPI) (McKee et al. 1993), and contains two steps: (1) choose a suitable probability distribution function (PDF) to fit the aggregated streamflow data over the time scale of interest (e.g., 1, 3, 6, 12, 24 months); (2) obtain the SSI value by inverse normal function, with a mean of zero and a standard deviation of one, of the above cumulative probability functions. In this study, the SSI at the time scale of 3 months is considered, as it is appropriate for capturing the seasonal dry/wet conditions.
The details of the computation of SSI have been previously reported (Vicente-Serrano et al. 2014). The classification of SSI is analogous to that of SPI. According to National Standard of the People's Republic of China, the classification of meteorological drought (using SPI) posits: the near normal condition as $(-0.49 \leqslant \mathrm{SPI} \leqslant 0.49)$. In the current study, the threshold of the droughts/floods condition is set to 0.49: drought (SSI $<-0.49$ ), near normal $(-0.49 \leqslant \mathrm{SSI} \leqslant 0.49)$ and flood $(\mathrm{SSI}>0.49)$.

\subsection{Copula distribution functions}

In this paper, the structure and joint distribution of drought and flood variables are simulated with copula theory. Copula is a multivariate distribution function that links joint probability to their corresponding one-dimensional marginal distributions. According to Sklar (1973), in terms of the bivariate case, if $H$ is a bivariate distribution function of two correlated random variables of $X$ and $Y$, each with a marginal distribution functions $F$ and $G$, then there exists a copula $C$ such that

$$
H(x, y)=C(F(x), G(y)) .
$$

If $F$ and $G$ are continuous, then the copula $C$ is unique and has the representation:

$$
C=H\left(F^{-1}(x), G^{-1}(y)\right)
$$

where $F^{-1}$ and $G^{-1}$ are the inverse functions of $F$ and $G$.

Conversely, for any univariate marginal distribution function, $F$ and $G$, and any copula, the function $H$ defined above is a two-dimensional distribution function with marginal functions $F$ and $G$. A more detailed treatment of copulas and their properties can be found in Joe (1997) and Nelson (2006).

Copulas can be classified into several families and Archimedean copulas are of particular interests in hydrology. In this study, the Gumbel, Clayton and Frank copula from the Archimedean family are employed to model joint dependence of droughts and floods variables. The expressions for PDF and associated parameter space of bivariate copulas are presented in table 1 .

\subsection{Multivariate L-moments}

The multivariate L-moments were developed by Serfling and Xiao (2007) based on the traditional univariate L-moments (Hosking and Wallis 1993, 
Table 1. Expression of PDF, associated parameter and parameter range of applied copulas.

\begin{tabular}{lll}
\hline Copulas & \multicolumn{1}{c}{$\mathrm{C}(u, v)$} & Parameter space \\
\hline Gumbel & $\exp \left\{-\left[(-\ln u)^{\theta}+(-\ln v)^{\theta}\right]^{1 / \theta}\right\}$ & {$[1, \infty)$} \\
Clayton & $\left(u^{-\theta}+v^{-\theta}-1\right)^{-1 / \theta}$ & $(0, \infty)$ \\
Frank & $-\frac{1}{\theta} \ln \left[1+\left(\mathrm{e}^{-\theta}-1\right)^{-1}\left(\mathrm{e}^{-\theta u}-1\right)\left(\mathrm{e}^{-\theta v}-1\right)\right]$ & $(-\infty, 0) \cup(0, \infty)$ \\
\hline
\end{tabular}

1997). Here, we briefly give the definition and computation of bivariate L-moments method. More detailed information is presented in Serfling and Xiao (2007). In this study, computations were conducted with the MATLAB program provided by Chebana et al. (2009) and the R software package 'Imomco' by Asquith (2015).

Let $X^{(j)}$ be a random variable with distribution $F_{j}$, for $j=1,2$. Then, the multivariate L-moments are matrices $\Lambda_{k}(k \geq 1)$ with elements defined by:

$$
\begin{gathered}
\lambda_{k[i j]}=\operatorname{Cov}\left(X^{(i)}, P_{k-1}^{*}\left(F_{j}\left(X^{(j)}\right)\right)\right), \\
i, j=1,2 \text { and } k=2,3, \ldots
\end{gathered}
$$

where $P_{k}^{*}$ is the so-called shifted Legendre polynomial. Then the L-moment coefficients are given by

$$
\tau_{k[12]}=\lambda_{k[12]} / \lambda_{2}^{(1)}, \quad \text { for } k \geq 3
$$

and

$$
\tau_{2[12]}=\lambda_{2[12]} / \lambda_{1}^{(1)}
$$

where $\lambda_{k}^{(j)}=\lambda_{k[j j]}$ is the classical $k$ th L-moment of the variable $X^{(j)}, j=1,2$ as defined by Hosking and Wallis $(1993,1997)$. Then, the matrix of the L-moment coefficients can be written as:

$$
\begin{aligned}
\Lambda_{k} & =\left(\tau_{k[i j]}\right)_{i, j=1,2}=\left(\begin{array}{ll}
\tau_{k[11]} & \tau_{k[12]} \\
\tau_{k[21]} & \tau_{k[22]}
\end{array}\right), \\
k & =2,3, \ldots
\end{aligned}
$$

and for $k=1$, the first order bivariate L-moment corresponds to the vector $\lambda_{1}=E\left(X^{(1)}, X^{(2)}\right)^{t}$.

\subsection{Discordance test}

The discordance test is useful for determining in advance whether the stations in a divided region are conspicuously discordant with the entire group (She et al. 2016b). Hosking and Wallis (1993) give the definition of discordancy of sites on the basis of L-moments, and Chebana and Ouarda (2007) extended it to the multivariate case.

Considering a matrix $U_{i}=\left(\Lambda_{2}^{i}, \Lambda_{3}^{i}, \Lambda_{4}^{i}\right)^{t}$ for each site $i$, that contains three matrices $\Lambda_{2}^{i}, \Lambda_{3}^{i}, \Lambda_{4}^{i}$ defined in equation (5). Then the following matrix $D_{i}$ is defined as:

$$
D_{i}=\left(U_{i}-\bar{U}\right)^{t} S^{-1}\left(U_{i}-\bar{U}\right) / 3
$$

where $\bar{U}=\sum_{i=1}^{N} U_{i} / N, S=\sum_{i=1}^{N}\left(U_{i}-\bar{U}\right)\left(U_{i}-\bar{U}\right)^{t} /$ $(N-1)$. In order to evaluate the discordancy of site $i$, it is possible to use the norm of the matrix. In this study, we employed the spectral norm $\|A\|_{2}$ to quantify the variability, Chebana and Ouarda (2007) suggested the constant $c=\chi_{1-0.05}(3) / 3=$ 2.60 as a critical value for $\left\|D_{i}\right\|$ considered for large regions.

\subsection{Homogeneity test}

The bivariate heterogeneity statistic $H_{\|\bullet\|}$, which measures a set of sites, is calculated as follows (Chebana and Ouarda 2007):

$$
H_{\|\bullet\|}=\frac{V_{\|\bullet\|}-\mu_{V \operatorname{sim}}}{\sigma_{V \operatorname{sim}}}
$$

where $\|\bullet\|$ is the spectral norm, $V_{\|\bullet\|}=$ $\sqrt{\sum_{i=1}^{N} n_{i}\left\|\Lambda_{2}^{i}-\Lambda_{2}^{R}\right\|^{2} / \sum_{i=1}^{N} n_{i}}$, and $\Lambda_{2}^{i}$ is the Lcovariance matrix for site $i$ with a record length $n_{i}, \quad i=1,2, \ldots, N, \Lambda_{2}^{R}=\sum_{i=1}^{N} n_{i} \Lambda_{2}^{i} / \sum_{i=1}^{N} n_{i}$. $\mu_{V \text { sim }}$ and $\sigma_{V \text { sim }}$ are the mean and standard deviation of the $N_{\text {sim }}$ value of $V_{\|\bullet\|}$ in the simulated regions, respectively.

The simulated regions are homogeneous with sites having the same record length as their observed counterparts. To avoid any subjective choice of the bivariate distribution with which simulations are carried out to compute $\mu_{V \operatorname{sim}}$ and $\sigma_{V \text { sim }}$, this bivariate distribution should be as general as possible and include most distributions commonly used in hydrology. Chebana and Ouarda (2007) suggested using the Gumbel-Hougaard (Gumbel) bivariate copula to produce the joint distribution and the Kappa distribution to simulate the marginal distributions. For this occasion, 1000 simulations were performed to validate the result (Hosking and Wallis 1993, 1997). In the present 
study, a region of sites was declared to be homogeneous if $H_{\|\bullet\|}<1$, acceptably homogeneous if $1<$ $H_{\|\bullet\|} \leq 2$ and definitely heterogonous if $H_{\|\bullet\|}>2$.

\subsection{Copula estimation for homogeneity regions and the regional risk assessment of the ADFEs}

In this study, the regional marginal distributions were fitted the traditional univariate L-moments method proposed by Hosking and Wallis (1993, 1997), meanwhile, and the bivariate copula functions for a homogeneous region were fitted using observations from all sites in the region. As the streamflow records in a single site are not large enough, this method can improve the reliability of statistical estimates.

Let $D$ and $F$ denote the variables of droughts and floods, respectively. From the definition of SSI, the value of 0.49 and -0.49 is the truncation level for the flood and drought, respectively. Then the following four joint probabilities of seasonal drought and flood events are considered in this study (Huang et al. 2014):

(1) Continuous droughts in spring-summer/summer-autumn (DD):

$$
P_{D D}=P(X<-0.49, Y<-0.49)
$$

(2) Continuous floods in spring-summer/summerautumn (FF):

$$
P_{F F}=P(X>0.49, Y>0.49)
$$

(3) Spring droughts and summer floods/summer droughts and autumn floods (DF):

$$
P_{D F}=P(X<-0.49, Y>0.49) ;
$$

(4) Spring floods and summer droughts/summer floods and autumn droughts (FD):

$$
P_{F D}=P(X>0.49, Y<-0.49) .
$$

\section{Study area and materials}

HRB is located in the eastern China between the Yangtze River Basin and the Yellow River Basin covering a total of approximately $270,000 \mathrm{~km}^{2}$ (Wu et al. 2017). The long-term average annual precipitation in the basin is approximately $880 \mathrm{~mm}$, with more than $50 \%$ occurring during the flooding

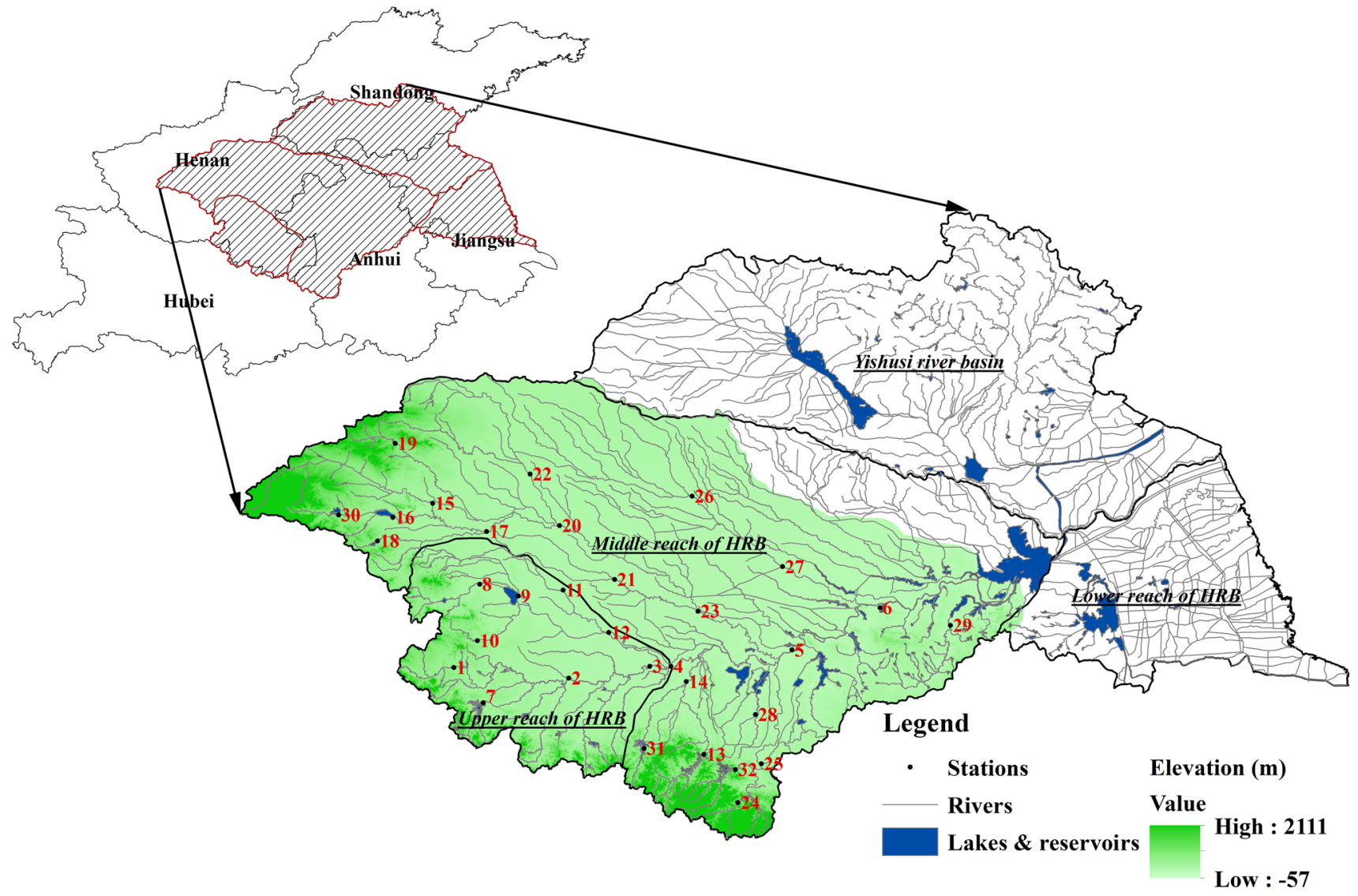

Figure 1. Location of HRB and the hydrological stations used in the study area. 
Table 2. Some detailed information of the hydrological stations in the study area.

\begin{tabular}{|c|c|c|c|c|c|c|c|c|}
\hline$\#$ & Name & $\begin{array}{l}\text { Long. } \\
\left({ }^{\circ} \mathrm{E}\right)\end{array}$ & $\begin{array}{l}\text { Lat. } \\
\left({ }^{\circ} \mathrm{S}\right)\end{array}$ & $\begin{array}{l}\text { Ele } \\
(\mathrm{m})\end{array}$ & $\begin{array}{c}\text { Area } \\
\left(\mathrm{km}^{2}\right)\end{array}$ & $\begin{array}{l}\text { MAP } \\
(\mathrm{mm})\end{array}$ & $\begin{array}{c}\text { MASF } \\
\left(10^{6} \mathrm{~m}^{3}\right)\end{array}$ & $\begin{array}{l}R L \\
(a)\end{array}$ \\
\hline 1 & Dapoling & 113.75 & 32.42 & 104 & 1640 & 993 & 601 & 57 \\
\hline 2 & Xixian & 114.73 & 32.33 & 43 & 10190 & 993 & 3651 & 57 \\
\hline 3 & Huaibin & 115.42 & 32.43 & 34 & 16005 & 951 & 5444 & 55 \\
\hline 4 & Wangjiaba & 115.60 & 32.43 & 28 & 30630 & 998 & 9037 & 57 \\
\hline 5 & Lutaizi & 116.63 & 32.57 & 21 & 88630 & 949 & 21387 & 55 \\
\hline 6 & Bengbu & 117.38 & 32.93 & 26 & 121330 & 976 & 26372 & 57 \\
\hline 7 & Nanwan & 114.00 & 32.12 & 98 & 1090 & 1147 & 430 & 53 \\
\hline 8 & Suiping & 113.97 & 33.13 & 68 & 1760 & 915 & 529 & 55 \\
\hline 9 & Suyahu & 114.30 & 33.03 & 56 & 4715 & 933 & 1156 & 53 \\
\hline 10 & Boshan & 113.95 & 32.65 & 143 & 578 & 930 & 155 & 55 \\
\hline 11 & Miaowan & 114.68 & 33.08 & 44 & 2660 & 892 & 603 & 55 \\
\hline 12 & Bantai & 115.07 & 32.72 & 36 & 11280 & 951 & 2607 & 57 \\
\hline 13 & Meishan & 115.88 & 31.68 & 215 & 1970 & 1394 & 1375 & 45 \\
\hline 14 & Jiangjiaji & 115.73 & 32.30 & 30 & 5930 & 1093 & 2034 & 55 \\
\hline 15 & Dachen & 113.57 & 33.82 & 80 & 5550 & 755 & 770 & 55 \\
\hline 16 & Baiguishan & 113.23 & 33.70 & 96 & 2730 & 747 & 528 & 57 \\
\hline 17 & Luohe & 114.03 & 33.58 & 63 & 12150 & 775 & 2116 & 57 \\
\hline 18 & Gushitan & 113.10 & 33.50 & 165 & 286 & 977 & 78 & 48 \\
\hline 19 & Baisha & 113.25 & 34.33 & 207 & 962 & 686 & 56 & 57 \\
\hline 20 & Zhoukou & 114.65 & 33.63 & 51 & 25800 & 782 & 3121 & 57 \\
\hline 21 & Shenqiu & 115.12 & 33.17 & 40 & 3094 & 889 & 585 & 49 \\
\hline 22 & Fugou & 114.40 & 34.07 & 58 & 5710 & 722 & 547 & 57 \\
\hline 23 & Fuyang & 115.83 & 32.90 & 28 & 35246 & 915 & 4452 & 51 \\
\hline 24 & Bailianya & 116.17 & 31.27 & 242 & 747 & 1413 & 596 & 54 \\
\hline 25 & Hengpaitou & 116.37 & 31.60 & 55 & 4370 & 1251 & 3372 & 57 \\
\hline 26 & Boxian & 115.78 & 33.88 & 38 & 10573 & 801 & 768 & 45 \\
\hline 27 & Mengcheng & 116.55 & 33.28 & 30 & 15475 & 873 & 1320 & 45 \\
\hline 28 & Guzhen & 116.32 & 32.02 & 27 & 4541 & 867 & 865 & 45 \\
\hline 29 & Mingguang & 117.98 & 32.78 & 33 & 3501 & 989 & 662 & 57 \\
\hline 30 & Zhaopingtai & 112.77 & 33.72 & 178 & 1416 & 854 & 478 & 57 \\
\hline 31 & Nianyushan & 115.37 & 31.73 & 101 & 924 & 1245 & 559 & 30 \\
\hline 32 & Xianghongdian & 116.15 & 31.55 & 271 & 1430 & 1412 & 1074 & 45 \\
\hline
\end{tabular}

Note. MAP: mean annual precipitation, MASF: mean annual streamflow, and RL: record lengths of precipitation and streamflow.

season (June-September)(Liu et al. 2016). The HRB is located in the north-south climate transitional zone in China, with the southern HRB belonging to the subtropical zone and the northern area belonging to the warm temperate zone. The annual precipitation exhibits a large decadal variability. The maximum and minimum annual precipitation differ by four to five-fold in some regions. Annual precipitation is more than $1400 \mathrm{~mm}$ in the southern mountainous region, compared to 1000 $1200 \mathrm{~mm}$ in the western mountainous region and $600-700 \mathrm{~mm}$ in the northern region. Droughts and floods occur frequently in this basin, and largely influence the natural systems and human lives (She et al. 2016a).

The HRB contains two water systems, i.e., the Huai River system and the Yi-Shu-Si River system.
In our study, special consideration is given to the area above the Zhongdu hydrological station on the upper-middle reach region. The monthly streamflow data at 32 hydrological stations from 1956 to 2012 in this region (figure 1) are provided by the Bureau of Hydrology of HRC, and some detailed information is presented in table 2 .

\section{Results}

\subsection{Intra-annual distribution of streamflow}

Figure 2 shows the intra-annual distribution of streamflow at each hydrological station in our study area. The summer streamflow (June-August) makes the largest contribution to the annual streamflow, with a proportional contribution 


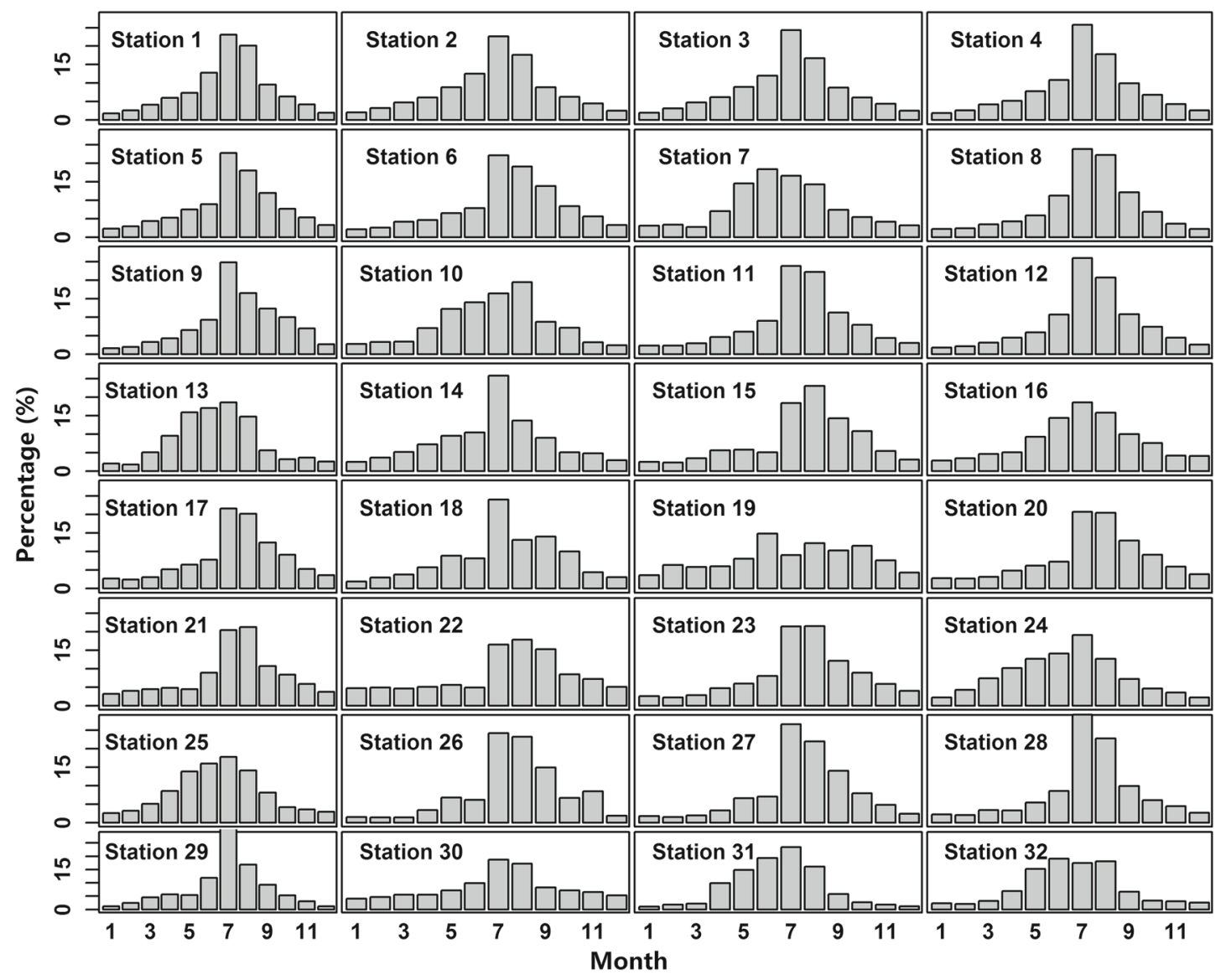

Figure 2. Intra-annual distribution of streamflow in each station.

ranging from 36.65 to $62.09 \%$ (with an average of more than 51\%) The autumn (SeptemberNovember) streamflow and spring (March-May) streamflow contribute approximately 22 and $18 \%$ to the annual streamflow. Finally, winter (DecemberFebruary) streamflow contribute $<8 \%$ to the annual streamflow, the smallest among the four seasons. The intra-year distribution of the streamflow is similar to the distribution of precipitation in the HRB, which can be seen in He et al. (2015). Considering that winter streamflow is almost always the smallest streamflow in any given year, our attention will mainly be focused on the droughts and floods during the remaining three seasons.

The SSI at a 3-month scale are calculated for each station in the HRB according to their definition. Here, the Pearson type III distribution was selected to fit the monthly streamflow time series as it is widely used and quite suitable for streamflow simulations in China (Hong et al. 2015). The spring, summer and autumn SSIs are characterized by the SSI values in May, August and November, respectively. Figure 3 shows the variations of the
SSI time series at three random stations, Nos. 6, 20 and 28, in the mainstream, the north part of Henan province and the south part of Anhui province, respectively. From figure 3, we can observe distinct seasonal continuous drought events, continuous flood events and ADFEs at all stations.

A continuous drought event can be observed to stretch over spring, summer and autumn in 1994 at the three stations, which was also reported in Zhang (2008). An obvious continuous flood event can be found in No. 6 station in 2003, which is consistent with the results in Liu (2012). According to the Bureau of Hydrology of HRB, the rainfall in 2003 was extremely abundant, and the anomalously high precipitation during the spring of 2003, as well as the southward-shifted subtropical anticyclone in July 2003, directly caused extreme floods throughout the HRB. Finally, a typical ADFE can be observed between spring and summer in 1982 in station No. 20. In April 1982, Henan province underwent a spring drought with high temperature and little precipitation across the entire province. This drought continued to mid-July, and ultimately 


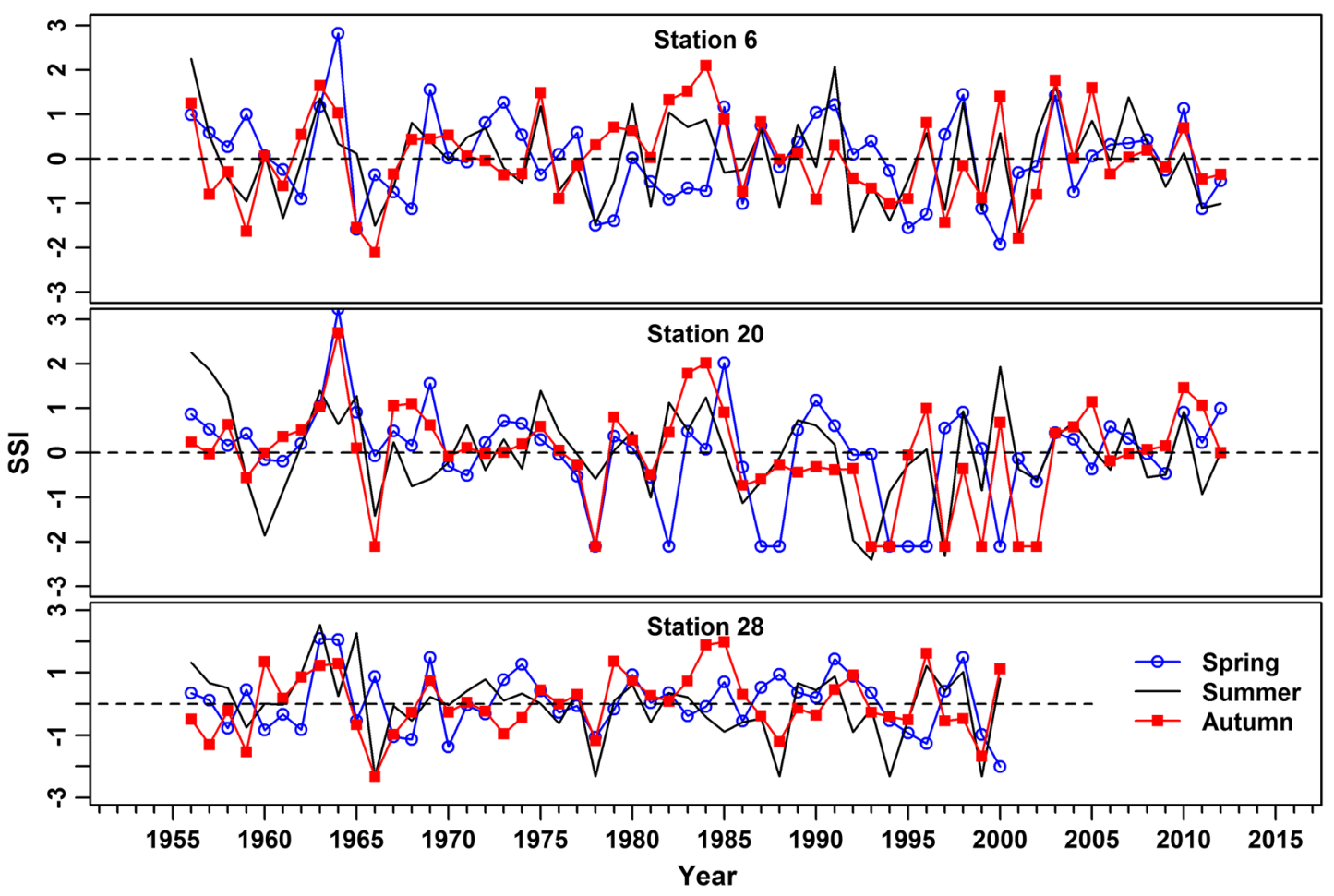

Figure 3. SSI time series of three random stations.

led to thorough desiccation of many rivers and weirs in Henan province. After July 12, three consecutive heavy storms stuck Henan province, and this caused sudden flood events in the region. Moreover, a similar but even more severe ADFE between spring and summer also occurred in 2000 at the same station, which was caused by the strengthened pattern of the winter El Nino in the equatorial east Pacific (Bu and Jia 2004).

\subsection{Regionalization of SSI series based on the multivariate L-moments}

The homogeneous regions were initially divided into five sub-regions by the fuzzy c-means cluster method with six indicators, including longitude, latitude, elevation, drainage area, mean annual precipitation and mean annual streamflow (table 2). Then, both the univariate and multivariate discordancy tests were performed in all of the above five regions using the seasonal SSI time series obtained in section 4.1. Some subjective adjustments were also used to make the division more appropriate and guarantee the homogeneity of the sub-regions. The final identified regions are given in tables 3 and 4. Notably, the station No. 32 could not be grouped into any of the above sub-regions, therefore, it was excluded from the following analysis.
As shown in table 3, both the univariate and bivariate discordancy value of each site in each sub-region were less than the related critical value. Both the univariate homogeneity statistics described in Hosking and Wallis $(1993,1997)$ and the bivariate homogeneity statistics described in section 2.5 illustrated in table 4 were $<1$, the above results indicated that all the identified sub-regions were statistically corroborated to be homogeneous.

\subsection{Choice of optimal regional frequency distribution}

After identifying the homogeneity of the obtained sub-regions, we should choose the optimal regional distributions of both the marginal and bivariate joint distributions. An appropriate marginal distribution should be selected first in each homogeneous sub-region. In this study, three statistical probability distributions with two parameters (exponential (EXP), Gumbel (GUM) and normal (NORM)), and five statistical probability distributions with three parameters (Pearson type III (P-III), lognormal (LN3), generalized Pareto distribution (GPA), generalized logistic distribution (GLO) and generalized extreme value distribution (GEV)), were selected as the candidate distributions to fit the spring, summer and autumn SSI time series in all homogeneous sub-regions. 
Table 3. Results of regional discordancy D for the seasonal SSI in each sub-region.

\begin{tabular}{|c|c|c|c|c|c|c|}
\hline \multirow[b]{2}{*}{ Region } & \multirow{2}{*}{$\begin{array}{l}\text { Site } \\
\text { no. }\end{array}$} & \multicolumn{3}{|c|}{ Univariate statistics } & \multicolumn{2}{|c|}{ Bivariate statistics } \\
\hline & & D5 & D8 & D11 & $\mathrm{D} 5,8$ & D8, 11 \\
\hline \multirow[t]{6}{*}{ I (1.65) } & 1 & 1.36 & 0.97 & 1.49 & 0.99 & 1.22 \\
\hline & 2 & 0.93 & 1.39 & 0.23 & 0.99 & 1.16 \\
\hline & 3 & 0.11 & 0.88 & 0.27 & 0.87 & 1.13 \\
\hline & 4 & 0.57 & 0.93 & 1.62 & 1.19 & 1.38 \\
\hline & 5 & 1.63 & 0.59 & 0.78 & 1.31 & 0.93 \\
\hline & 6 & 1.4 & 1.23 & 1.61 & 1.16 & 0.98 \\
\hline \multirow[t]{7}{*}{ II (1.92) } & 7 & 1.28 & 1.33 & 1.66 & 1.19 & 1.45 \\
\hline & 8 & 1.12 & 0.19 & 1.01 & 1.01 & 1.3 \\
\hline & 14 & 0.54 & 0.57 & 0.76 & 0.88 & 1.68 \\
\hline & 15 & 0.67 & 1.42 & 0.99 & 1.43 & 1.17 \\
\hline & 16 & 1.13 & 1.01 & 1.78 & 1.28 & 1.55 \\
\hline & 17 & 0.64 & 1.08 & 0.24 & 0.98 & 0.76 \\
\hline & 20 & 1.62 & 1.38 & 0.57 & 1.1 & 1.33 \\
\hline \multirow[t]{8}{*}{ III (2.14) } & 9 & 0.32 & 1.3 & 1.96 & 1 & 1.65 \\
\hline & 11 & 1.28 & 0.42 & 1 & 0.87 & 0.73 \\
\hline & 18 & 0.59 & 0.41 & 1.04 & 1.21 & 1.19 \\
\hline & 21 & 0.54 & 1.14 & 0.35 & 1.08 & 0.22 \\
\hline & 22 & 1.85 & 1.02 & 1.95 & 1.77 & 1.57 \\
\hline & 24 & 0.92 & 1.73 & 0.7 & 1.72 & 1.87 \\
\hline & 25 & 1.24 & 0.79 & 0.21 & 1.29 & 0.98 \\
\hline & 26 & 1.27 & 1.19 & 0.8 & 1.14 & 1.84 \\
\hline \multirow[t]{5}{*}{ IV (1.33) } & 10 & 1.08 & 1.28 & 1.25 & 1.04 & 0.98 \\
\hline & 12 & 1.22 & 1.15 & 1.31 & 0.83 & 1.07 \\
\hline & 13 & 1.08 & 0.71 & 0.86 & 0.93 & 0.82 \\
\hline & 30 & 1.24 & 1.01 & 1.33 & 1.02 & 1.03 \\
\hline & 31 & 0.38 & 0.86 & 0.25 & 0.87 & 0.98 \\
\hline \multirow[t]{5}{*}{$\mathrm{V}(1.33)$} & 19 & 1.25 & 0.19 & 1.22 & 0.64 & 1.06 \\
\hline & 23 & 1.33 & 1.21 & 1.21 & 1.06 & 0.92 \\
\hline & 27 & 1.13 & 1.32 & 0.7 & 0.98 & 0.63 \\
\hline & 28 & 1.16 & 1.26 & 1.32 & 1.02 & 1.07 \\
\hline & 29 & 0.13 & 1.02 & 0.56 & 1.04 & 1.04 \\
\hline
\end{tabular}

Note: Numbers 5, 8 and 11 represent spring, summer and autumn, respectively; the univariate discordancy critical values are displayed in parenthesis while the bivariate discordancy critical values are all 2.60 .

Table 4. Results of regional heterogeneity $H$ for the seasonal SSI in each sub-region.

\begin{tabular}{lrrrrrr}
\hline & \multicolumn{3}{c}{ Univariate statistics } & & \multicolumn{2}{c}{ Bivariate statistics } \\
\cline { 2 - 3 } Region & \multicolumn{1}{c}{ H5 } & H8 & H11 & & H5, 8 & H8, 11 \\
\hline I & 0.018 & -0.149 & 0.249 & & 0.04 & 0.008 \\
II & -0.084 & 0.007 & 0.015 & & 0.236 & 0.002 \\
III & 0.520 & -0.056 & 0.117 & & 0.009 & 0.126 \\
IV & 0.224 & 0.104 & -0.122 & & 0.107 & 0.271 \\
V & 0.039 & -0.023 & -0.032 & & -0.056 & -0.032 \\
\hline
\end{tabular}

Selection of an optimal distribution is considered to be an important procedure in the regional frequency analysis. In the present study, both the
Hosking and Wallis $(1993,1997)$ statistic $Z_{D I S T}$ and the L-kurtosis criterion L-K developed by Pandey et al. (2001) were considered and the 
Table 5. Results of goodness-of-fit test for the candidate distributions in different regions and different seasons.

\begin{tabular}{|c|c|c|c|c|c|}
\hline Season & Region & $\begin{array}{l}\text { Acceptable distributions } \\
\text { in ascending order } \\
\quad\left(\left|Z_{D I S T}\right| \leq 1.64\right)\end{array}$ & $\begin{array}{l}\text { Best distribution } \\
\qquad(\min |Z|)\end{array}$ & $\operatorname{Min}(\mathrm{L}-\mathrm{K})$ & $\begin{array}{c}\text { Selected } \\
\text { DIST }\end{array}$ \\
\hline \multirow[t]{5}{*}{ Spring } & I & LN3, GLO & LN3 (0.904) & 0.0163 & LN3 \\
\hline & II & GLO & GLO $(0.665)$ & 0.0126 & GLO \\
\hline & III & LN3, NORM & LN3 (0.802) & 0.0126 & LN3 \\
\hline & IV & GLO, P-III, NORM & GLO (0.925) & 0.0209 & GLO \\
\hline & $\mathrm{V}$ & GLO, LN3, NORM & GLO $(0.741)$ & 0.0174 & GLO \\
\hline \multirow[t]{5}{*}{ Summer } & I & $*$ & $\operatorname{GEV}(2.510)$ & 0.0374 & GEV \\
\hline & II & GLO, LN3, NORM & GLO (0.960) & 0.0185 & GLO \\
\hline & III & GLO & GLO (0.654) & 0.0118 & GLO \\
\hline & IV & LN3, NORM, GEV, GLO & LN3 (0.167) & 0.0035 & LN3 \\
\hline & $\mathrm{V}$ & GLO, NORM, LN3 & GLO (0.904) & 0.0205 & NORM \\
\hline \multirow[t]{5}{*}{ Autumn } & $\mathrm{I}$ & GLO & GLO (0.569) & 0.0114 & GLO \\
\hline & II & GLO & GLO (1.329) & 0.0248 & GLO \\
\hline & III & GLO & GLO $(0.371)$ & 0.0071 & GLO \\
\hline & IV & LN3, GEV, GLO & LN3 (0.359) & 0.0074 & LN3 \\
\hline & $\mathrm{V}$ & LN3, NORM, GLO, GEV & LN3 (0.589) & 0.0121 & LN3 \\
\hline
\end{tabular}

Note: $*$ represents that there is no distribution with the statistics $\left|Z_{D I S T}\right|<1.64$.

results of the goodness-of-fit test were presented in table 5. According to Hosking and Wallis (1993, 1997), the fit of a candidate statistical probability distribution can be treated as the true underlying frequency distribution if the absolute value of goodness-of-fit measure of $Z_{D I S T}$ statistic is no more than 1.64, corresponding to a confidence level of $90 \%$, under the hypothesis that the sites in the region are independent with each other; if serial dependence exists in the dataset, the statistic $Z_{D I S T}$ could be overestimated, if more than one statistical probability distribution satisfies the measure of $\left|Z_{D I S T}\right| \leq 1.64$, then the one with the smallest $\left|Z_{D I S T}\right|$ should be chosen as the optimal distribution. Meanwhile, according to Pandey et al. (2001), the optimal distribution should be the one who has the smallest L-K statistic.

From table 5, we can find that two or more candidate distributions $\left(\left|Z_{D I S T}\right| \leq 1.64\right)$ could fit the SSI series in each season very well, but the best fit distribution is the one with the smallest $\left|Z_{D I S T}\right|$, and will ultimately be adopted. Therefore, such procedure indicates that it is a very important step to undertake thorough distribution selection processes rather than only subjectively fit one single distribution for all SSI series so as to reduce the uncertainty originated from the choice of the 'best-fit' distribution for the considered SSI series (She et al. 2016b).
In particular, GLO and LN3 perform very well in fitting the regional SSI series in the study region. GLO is found to be acceptable 13 times over all five homogeneous regions from spring to autumn, while LN3, NORM, GEV and P-III are acceptable 8, 7, 3 and 1 times, respectively. GPA, EXP and GAM, are not acceptable for any of the circumstances because the absolute value of $Z_{D I S T}$ statistic are more than 1.64. None of the candidate distributions should be employed as the regional distribution of summer SSI series in Region I; however, if there exists serial dependence in the datasets, the statistic $Z_{D I S T}$ will often be overestimated (Hosking and Wallis 1993, 1997). Furthermore, the results from the L-K statistic are basically consistent with those from the $\left|Z_{D I S T}\right|$ statistics measure except for the summer SSI series in Region V, where the best fit distribution is GLO and NORM suggested by the $\left|Z_{D I S T}\right|$ statistic and L-K statistics, respectively. However, because GLO is widely accepted under most occasions in our study area, we finally chose this distribution to fit the summer SSI series in Region V.

Then, the parameters of the optimal distributions are estimated for each site using the L-moments method, which is shown in table 6 . The K-S test shows that all the distributions are acceptable under the significance level of 0.05 . 


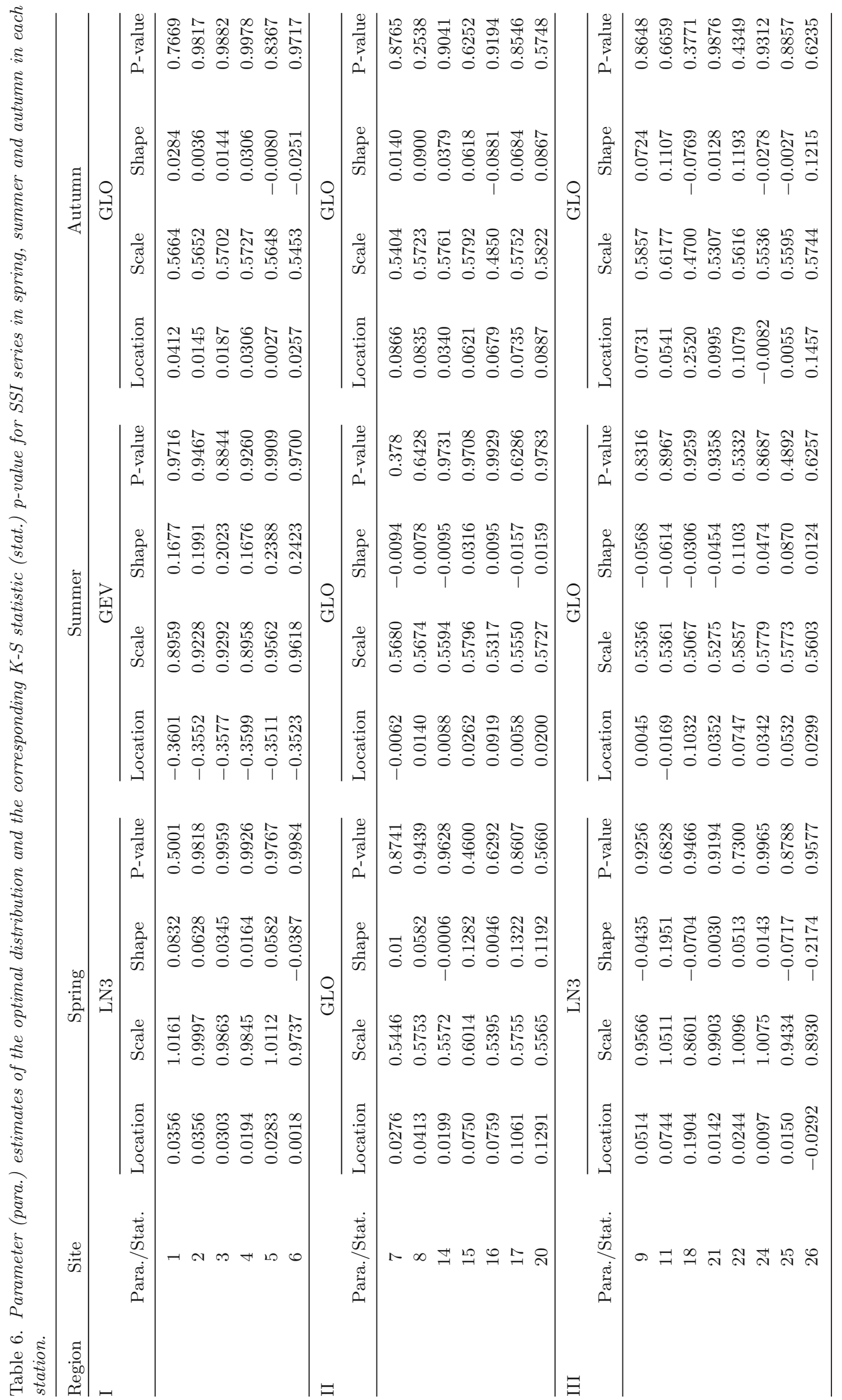




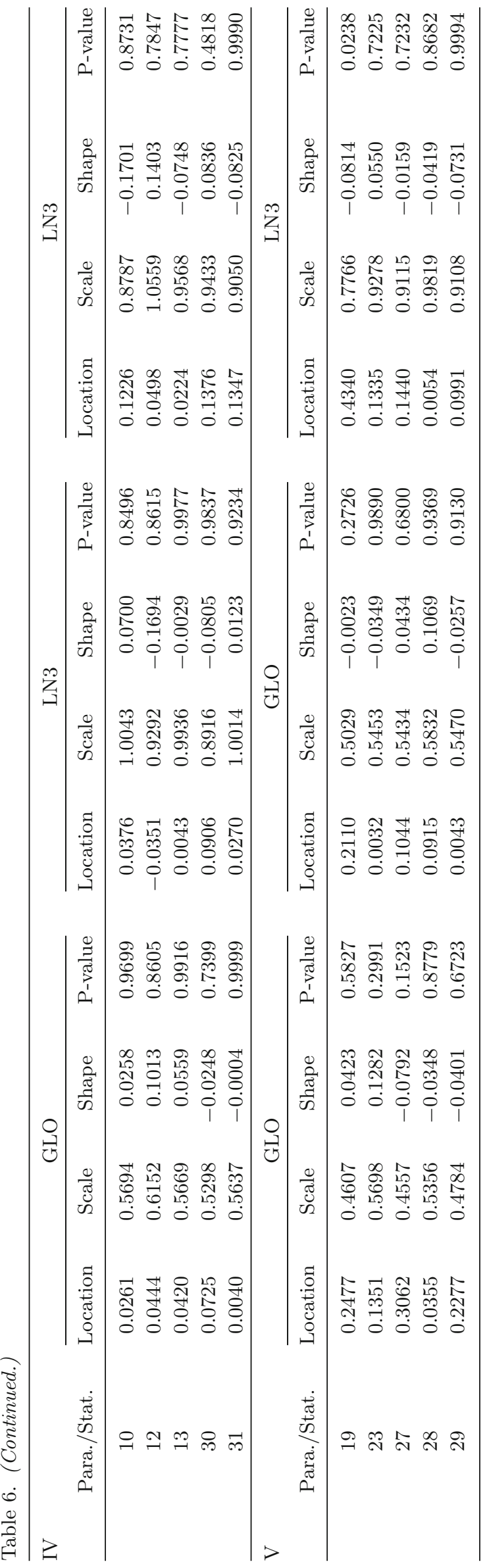

In our study, the parameter of the copula functions was estimated using the method introduced in Chebana et al. (2009) and Zhang et al. (2015). Goodness-of-fit tests for copulas based on Kendall's transform with the test statistic of the Cramérvon Mises functional $S_{n}^{C}$ defined in equation (9) of Genest et al. (2009) were calculated for each homogeneous region.

The parameter of each copula function and the corresponding $p$-value in each sub-region were given in table 7 . At $99 \%$ confidence level, each of the three selected copulas can be employed as the joint distribution except for the Clayton copula in Region IV during spring and summer. However, the best fit copulas for the homogeneous regions was the Frank copula because its $p$-value was larger than that of the Gumbel and Clayton copulas in most situations aside from the cases in Region $\mathrm{I}$ and $\mathrm{V}$ of spring and summer. Therefore, the Frank copula function was determined to be the best fit copulas for all sites in this study, and the parameters of this copula are shown in table 8 .

\subsection{Frequency analysis results}

The joint probabilities of ADFE events were computed at each site in the study area and the results are given in table 8 .

In both spring-summer and summer-autumn, $\mathrm{DD}$ and FF events occurred more frequently than DF and FD events. The average probabilities of FF events are 13.78 and $17.06 \%$ during springsummer and summer-autumn, while they are 11.27 and $13.79 \%$ for DD events, respectively. We find that FF events are more common than DD events. $\mathrm{DD}$ and FF events are slightly more frequent in summer-autumn than in spring-summer, with average probabilities of 13.79 and $17.06 \%$ in summer-autumn, respectively. That the average probabilities of spring-summer and summer-autumn ADFEs are 36.44 and $37.83 \%$, respectively, which indicates that ADFEs are slightly more likely to occur in summer-autumn than in springsummer.

The frequencies of all events are interpolated into the entire study area using the inverse distance weighing method (figure 4). Figure 4 shows that the drought and flood events are most likely to occur near the mainstream. Moreover, the frequency of drought and flood events is higher in summer-autumn than in springsummer. 
Table 7. Results of the copula parameters and goodness-of-fit test of regional joint distribution.

\begin{tabular}{|c|c|c|c|c|c|c|c|c|c|c|}
\hline \multirow[b]{2}{*}{ Copulas } & \multicolumn{2}{|c|}{ Region I } & \multicolumn{2}{|c|}{ Region II } & \multicolumn{2}{|c|}{ Region III } & \multicolumn{2}{|c|}{ Region IV } & \multicolumn{2}{|c|}{ Region V } \\
\hline & Para. & p-val. & Para. & p-val. & Para. & p-val. & Para. & p-val. & Para. & p-val. \\
\hline \multicolumn{11}{|c|}{ Spring-summer } \\
\hline Gumbel & 1.213 & 0.4 & 1.234 & 0.023 & 99 & 0.238 & 1.224 & 0.013 & 1.172 & 0.165 \\
\hline Clayton & 0.426 & 0.499 & 0.467 & 0.019 & 0.398 & 0.292 & 0.447 & 0.005 & 0.345 & 0.158 \\
\hline Frank & 1.620 & 0.487 & 1.755 & 0.024 & 1.529 & 0.340 & 1.690 & 0.013 & 1.347 & 0.155 \\
\hline \multicolumn{11}{|c|}{ Summer-autumn } \\
\hline Gumbel & 1.691 & 0.519 & 1.379 & 0.025 & 1.489 & 0.038 & 1.374 & 0.237 & 1.353 & 0.261 \\
\hline Clayton & 1.382 & 0.612 & 0.757 & 0.025 & 0.977 & 0.055 & 0.748 & 0.280 & 0.706 & 0.343 \\
\hline Frank & 4.282 & 0.612 & 2.635 & 0.028 & 3.244 & 0.067 & 2.610 & 0.283 & 2.486 & 0.345 \\
\hline
\end{tabular}

Table 8. Frank copula parameter (para.) and the results of joint probability (percentage, \%) of ADFE in each station.

\begin{tabular}{|c|c|c|c|c|c|c|c|c|c|c|c|c|c|}
\hline \multirow[b]{2}{*}{ Region } & \multirow[b]{2}{*}{ Site } & \multicolumn{6}{|c|}{ Spring-summer } & \multicolumn{6}{|c|}{ Summer-autumn } \\
\hline & & Para. & DD & $\mathrm{FF}$ & $\mathrm{DF}$ & FD & $\mathrm{ADFE}$ & Para. & $\mathrm{DD}$ & FF & $\mathrm{DF}$ & FD & $\mathrm{ADFE}$ \\
\hline \multirow[t]{6}{*}{ I } & 1 & 1.5776 & 13.30 & 13.36 & 5.90 & 6.73 & 39.29 & 2.4174 & 14.21 & 14.64 & 4.86 & 4.04 & 37.75 \\
\hline & 2 & 1.9427 & 13.96 & 14.32 & 5.29 & 5.97 & 39.53 & 3.9806 & 17.39 & 17.42 & 2.63 & 2.36 & 39.80 \\
\hline & 3 & 1.1432 & 12.12 & 12.40 & 6.77 & 7.54 & 38.83 & 3.9089 & 17.36 & 17.43 & 2.76 & 2.45 & 40.00 \\
\hline & 4 & 1.8172 & 13.71 & 13.58 & 5.40 & 6.05 & 38.75 & 4.7080 & 18.47 & 18.59 & 2.04 & 1.68 & 40.79 \\
\hline & 5 & 1.4736 & 13.09 & 13.47 & 6.39 & 6.88 & 39.84 & 5.7181 & 20.05 & 20.01 & 1.26 & 1.20 & 42.52 \\
\hline & 6 & 1.7610 & 13.70 & 13.71 & 5.82 & 6.04 & 39.27 & 5.6461 & 19.15 & 20.13 & 1.34 & 1.11 & 41.74 \\
\hline \multirow[t]{7}{*}{ II } & 7 & 2.0547 & 12.71 & 13.32 & 4.43 & 4.88 & 35.33 & 0.4727 & 8.64 & 10.55 & 8.51 & 6.68 & 34.37 \\
\hline & 8 & 1.8380 & 12.39 & 13.50 & 5.09 & 5.36 & 36.35 & 3.0674 & 14.31 & 16.58 & 3.71 & 3.09 & 37.68 \\
\hline & 14 & 1.3838 & 11.25 & 12.05 & 5.75 & 5.91 & 34.96 & 2.4481 & 13.59 & 14.63 & 4.29 & 4.09 & 36.60 \\
\hline & 15 & 1.3173 & 11.43 & 13.17 & 6.24 & 6.75 & 37.58 & 3.3947 & 15.22 & 17.29 & 3.24 & 2.90 & 38.65 \\
\hline & 16 & 1.3353 & 9.03 & 13.32 & 5.70 & 5.42 & 33.48 & 2.6277 & 10.25 & 15.58 & 3.22 & 3.11 & 32.16 \\
\hline & 17 & 2.1485 & 12.38 & 14.76 & 4.20 & 5.21 & 36.55 & 3.1104 & 14.37 & 16.36 & 3.57 & 2.99 & 37.29 \\
\hline & 20 & 2.2279 & 12.08 & 15.48 & 3.95 & 5.26 & 36.77 & 3.6024 & 15.30 & 17.93 & 3.12 & 2.55 & 38.90 \\
\hline \multirow[t]{8}{*}{ III } & 9 & 0.9037 & 9.79 & 11. & 6.45 & 7.14 & 6 & & 15.39 & 17.65 & 2.57 & 2.21 & 37.82 \\
\hline & 11 & 2.2175 & 13.58 & 14.73 & 4.46 & 5.22 & 37.99 & 4.0776 & 16.84 & 17.63 & 2.47 & 2.15 & 39.09 \\
\hline & 18 & 1.2833 & 6.81 & 14.92 & 4.50 & 5.99 & 32.22 & 1.7197 & 5.80 & 16.45 & 5.46 & 2.81 & 30.53 \\
\hline & 21 & 1.1040 & 10.43 & 12.00 & 6.82 & 6.15 & 35.40 & 5.6034 & 15.67 & 20.53 & 1.12 & 0.86 & 38.18 \\
\hline & 22 & 1.5708 & 12.24 & 14.11 & 6.52 & 5.91 & 38.78 & 767 & 14.08 & 18.16 & 3.41 & 3.03 & 38.69 \\
\hline & 24 & 0.6708 & 10.55 & 11.34 & 8.10 & 7.75 & 37.75 & 1.7600 & 12.34 & 12.92 & 5.07 & 5.49 & 35.82 \\
\hline & 25 & 0.9794 & 10.54 & 12.02 & 7.08 & 6.88 & 36.52 & 1.3268 & 11.26 & 12.31 & 5.87 & 6.37 & 35.81 \\
\hline & 26 & 4.3472 & 16.74 & 17.60 & 2.04 & 1.81 & 38.19 & 7.0536 & 18.52 & 23.46 & 0.82 & 0.49 & 43.29 \\
\hline \multirow[t]{5}{*}{ IV } & 10 & 1.5602 & 12.21 & 13.51 & 6.10 & 5.99 & 37.81 & 3.4228 & 13.16 & 19.01 & 3.76 & 2.28 & 38.21 \\
\hline & 12 & 2.1373 & 14.01 & 14.26 & 4.75 & 5.33 & 38.35 & 4.0926 & 18.01 & 18.49 & 2.83 & 2.37 & 41.71 \\
\hline & 13 & 2.2082 & 13.66 & 14.66 & 4.65 & 5.05 & 38.02 & 1.4286 & 12.23 & 13.21 & 6.66 & 6.16 & 38.25 \\
\hline & 30 & 1.3277 & 8.84 & 13.55 & 5.77 & 5.39 & 33.55 & 1.8222 & 9.89 & 16.17 & 5.28 & 5.02 & 36.36 \\
\hline & 31 & 1.0909 & 11.34 & 12.06 & 7.08 & 6.71 & 37.19 & 2.2455 & 11.59 & 16.7 & 5.75 & 3.79 & 37.84 \\
\hline \multirow[t]{5}{*}{ V } & 19 & 1.0063 & 4.69 & 16.22 & 4.78 & 5.55 & 31.24 & 1.0872 & 2.96 & 20.3 & 7.25 & 2.72 & 33.24 \\
\hline & 23 & 2.0648 & 11.66 & 14.85 & 4.07 & 5.49 & 36.08 & 3.5138 & 13.87 & 17.98 & 3.41 & 2.19 & 37.45 \\
\hline & 27 & 1.9859 & 5.68 & 18.29 & 2.16 & 6.09 & 32.22 & 3.7499 & 12.61 & 20.18 & 2.70 & 2.20 & 37.69 \\
\hline & 28 & 0.5407 & 8.61 & 11.24 & 7.72 & 7.32 & 34.90 & 1.5438 & 11.86 & 13.98 & 5.63 & 6.67 & 38.14 \\
\hline & 29 & 1.2587 & 6.95 & 13.84 & 3.41 & 7.66 & 31.85 & 3.0616 & 13.12 & 16.68 & 3.81 & 2.64 & 36.25 \\
\hline
\end{tabular}



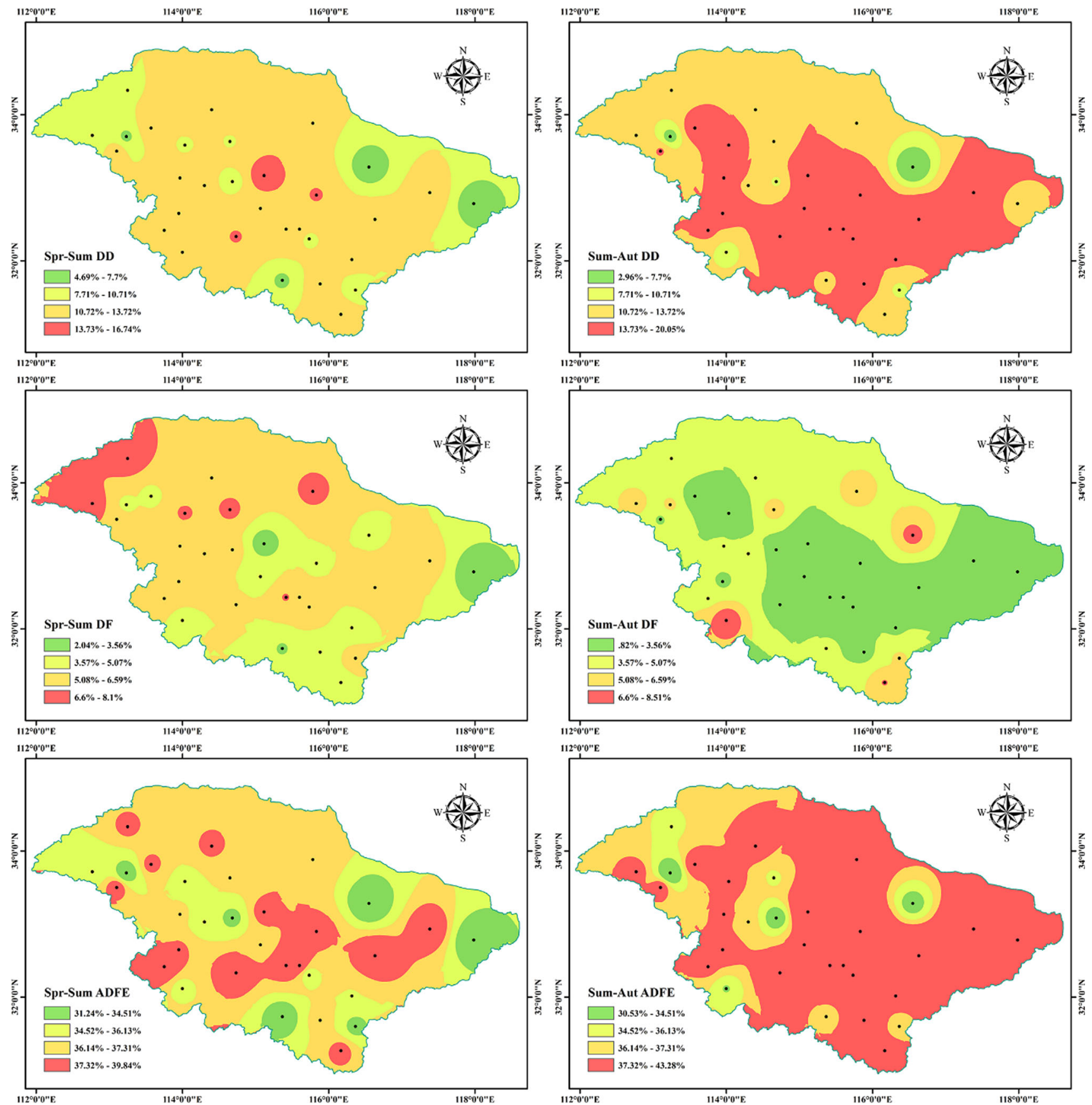

Figure 4. Spatial distribution of the probability of seasonal ADFEs on the HRB.

\section{Conclusions and discussion}

Extreme hydrological events, such as droughts and floods, are proven to be affected by many aspects and the multivariable tool is demonstrated to be an efficient way in modelling their statistical characteristics (Grimaldi and Serinaldi 2006; She et al. 2016a). In particular, under the current condition of global climate change, there will be more prolonged droughts or floods that will have a more severe impact on nature and also humanity.
In many regions of the world, events in which floods occur after a prolonged extreme drought or droughts occur after an extreme flood are found to occur more frequently. In this study, we define the sudden alternations between droughts and floods as ADFEs. However, the traditional univariate regional L-moment technique, which identifies the homogeneous region by taking only a single variable into consideration, is insufficient to fully characterize hydrological events with multivariate variables. Therefore, in this study, we concentrated 
on the joint probability characteristics of seasonal ADFEs using multivariate L-moments theory and bivariate copula functions. The HRB was chosen as the study area, and the droughts and floods from 1956 to 2012 at 32 meteorological stations were analyzed. The results are as follows:

(1) Summer streamflow makes the largest contribution to the annual streamflow, with an average of more than $51 \%$. The autumn streamflow and spring streamflow, contribute 22 and $18 \%$, respectively, and winter streamflow contribute $<8 \%$. Therefore, only droughts and floods in the spring, summer and autumn are discussed in this study.

(2) The entire study area was divided into five sub-regions using the fuzzy c-means cluster method. After the combined consideration of the univariate and multivariate discordancy and homogeneity test, some adjustments were adopted to make the division of the sub-regions homogeneous. Finally, we obtain five homogeneous sub-regions in the entire study area, which is appropriate for regional studies of floods and droughts.

(3) The GLO and LN3 are proven to be the optimal marginal distributions in modelling the SSI series in the spring, summer and autumn in most sub-regions. Our results also demonstrate the importance of considering a sufficient number of candidate distributions rather than one single distribution to reduce the uncertainty caused by the choice of optimal distribution. For the multivariable functions, the Frank copula is the most suitable choice, although the Gumbel, Clayton and Frank copulas were all capable of modelling the joint distribution for the spring-summer and summer-autumn SSI series in the study area.

(4) In both spring-summer and summer-autumn, FF events show the highest frequency, followed by DD events. The average probability of FF events are 13.78 and $17.06 \%$ during the springsummer and summer-autumn, while they are 11.27 and $13.79 \%$ for DD events, respectively. Additionally, the seasonal ADFEs are found to occur most likely near the mainstream of HRB, and seasonally, the summer-autumn droughts and floods occur more frequently than that in spring-summer.

In this study, the multivariate L-moments techniques are used to model seasonal hydrological droughts and floods alternation. However, a basic assumption of the multivariate regional frequency analysis is that the hydrological series are stationary, and therefore further investigations are needed on the consideration of non-stationarity in the streamflow series. The SSI is chosen to represent the dry/wet conditions in our study area; however, droughts and floods are influenced by many meteorological and hydrological factors, such as precipitation and evapo-transpiration. Hence, further studies can focus on the drought and flood descriptions with comprehensive consideration of other variables. The tail dependence is also very important in estimating the risk of multivariate hydrological extremes (Poulin et al. 2007). It is well known that different copula functions do have different abilities in capturing the tail dependence structure (Nelson 2006). For example, the Clayton copula is more suitable for modelling the dependence between the series with lower-tail dependence, while the Gumbel copula has a stronger ability in characterizing the dependence between the series with upper-tail dependence. More detailed consideration of the impact of different types of copula functions, more in terms of different tail dependence structures between the hydrological time series should be taken in subsequent studies.

\section{Acknowledgements}

This present study is financially supported by the National Natural Science Foundation of China (Grant No. 51279143; No.51369011), the Major Science and Technology Program for Water Pollution Control and Treatment (Grant No. 2014ZX07204006), the National Key Research and Development Program (during the 13th Five-year Plan), Ministry of Science and Technology, PRC (Grant 2016YFC0401301), and the Jiangxi Provincial Natural Science Foundation (Grant No. 20132 BAB203034). We are also very grateful to the Nature Research Editing Service for the good presentation of the paper.

\section{References}

Asquith W H 2015 lmomco: L-moments, trimmed L-moments, L-comoments, and many distributions; $\mathrm{R}$ package version 2.1.4, 4 .

Bond N R, Lake P S and Arthington A H 2008 The impacts of drought on freshwater ecosystems: An Australian perspective; Hydrobiologia 600 3-16.

Bu Y L and Jia J Y 2004 Influences of two patterns of El Nino (La Nina) on summer precipitation over Henan Province; Meteorol. J. Henan 2 11-13 (in Chinese). 
Burke E J and Brown S J 2010 Regional drought over the UK and changes in the future; J. Hydrol. 394(s3-4) 471-485.

Chebana F and Ouarda T B M J 2007 Multivariate Lmoment homogeneity test; Water Resourc. Res. 43(8) $199-212$.

Chebana F, Ouarda T B M J and Bruneau P 2009 Multivariate homogeneity testing in a northern case study in the province of Quebec, Canada; Hydrol. Process. 23(12) 1690-1700.

Dai A, Trenberth K E and Karl T R 1998 Global variations in droughts and wet spells: 1900-1995; Geophys. Res. Lett. 25(17) 3367-3370.

Devereux S 2007 The impact of droughts and floods on food security and policy options to alleviate negative effects; Agr. Econ. 37(s1) 47-58.

Genest C, Rémillard B and Beaudoin D 2009 Goodness-of-fit tests for copulas: A review and a power study; Insurance: Mathematics and Economics 44(2) 199-213.

Grimaldi S and Serinaldi F 2006 Asymmetric copula in multivariate flood frequency analysis; Adv. Water Resour. 29(8) 1155-1167.

Guhathakurta P, Sreejith O P and Menon P A 2011 Impact of climate change on extreme rainfall events and flood risk in India; J. Earth Syst. Sci. 120 359-373.

He Y, Ye J and Yang X 2015 Analysis of the spatio-temporal patterns of dry and wet conditions in the Huai River Basin using the standardized precipitation index; Atmos. Res. $166120-128$.

Hrdinka T, Novický O and Hanslík E et al. 2012 Possible impacts of floods and droughts on water quality; J. Hydroenviron. Res. 6 145-150.

Hong X, Guo S and Zhou Y 2015 Uncertainties in assessing hydrological drought using streamflow drought index for the upper Yangtze River basin; Stoch. Environ. Res. Risk Assess. 29(4) 1235-1247.

Hosking J R M and Wallis J R 1993 Some statistics useful in regional frequency analysis; Water Resour. Res. 29(29) 271-282.

Hosking J R M and Wallis J R 1997 Regional frequency analysis: An approach based on L-moments; Cambridge University Press, Cambridge.

Huang S, Hou B and Chang J 2014 Copulas-based probabilistic characterization of the combination of dry and wet conditions in the Guanzhong Plain, China; J. Hydrol. 519 3204-3213.

Huang S, Krysanova V and Hattermann F 2015 Projections of climate change impacts on floods and droughts in Germany using an ensemble of climate change scenarios; Regional Environ. Change 15 461-473.

Ivett P, Veronika B and Gábor S et al. 2013 Effects of extreme weather on reproductive success in a temperatebreeding songbird; PLOS I 8(11) e80033, 1-13.

Ji Y, Zhou G and Wang S et al. 2015 Increase in flood and drought disasters during 1500-2000 in southwest China; Natural Hazards 77 1-9.

Joe H 1997 Multivariate models and dependence concept; Chapman \& Hall, London.

Leigh C, Bush A and Harrison E T et al. 2014 Ecological effects of extreme climatic events on riverine ecosystems: Insights from Australia; Freshw. Biol. 76 648-657.
Li X and Ye X 2015 Spatiotemporal characteristics of drywet abrupt transition based on precipitation in Poyang Lake Basin, China; Water 7 1943-1958.

Liu H B 2012 Numerical simulation of the heavy rainfall in the Yangtze-Huai River Basin during summer 2003 using the WRF model; Atmos. Ocean. Sci. Lett. 5(1) 20-25.

Liu J, Zhang X and Xia J et al. 2016 Characterizing and explaining spatio-temporal variation of water quality in a highly disturbed river by multi-statistical techniques; Springer-Plus 5(1) 1171, doi: 10.1186/s40064-016-2815-z.

McKee T B N, Doesken J and Kleist J 1993 The relationship of drought frequency and duration to time scales; In: Eighth Conference on Applied Climatology, American Meterological Society, Boston, MA, pp. 179-184.

$\mathrm{Mu}$ W, Yu F and Xie Y et al. 2014 The copula function-based probability characteristics analysis on seasonal drought \& flood combination events on the north China Plain; Atmosphere 5(4) 847-869.

Nelson R B 2006 An introduction to copulas, 2nd edn, Berlin, Springer.

Pandey M D, Gelder P V and Vrijling J K 2001 Assessment of an L-kurtosis-based criterion for quantile estimation; J. Hydrol. Eng. 6(4) 284-292.

Parry M, Canziani O and Palutikof J et al. 2007 Climate change 2007: Impacts, adaptation and vulnerability; Contribution of Working Group II to the fourth assessment report of the Intergovernmental Panel on Climate Change, Cambridge University Press, Cambridge.

Pederson G T, Gray S T and Fagre D B et al. 2009 Longduration drought variability and impacts on ecosystem services: A case study from Glacier National Park, Montana; Earth Interactions 10 101-111.

Poulin A, Huard D and Favre A C et al. 2007 Importance of tail dependence in bivariate frequency analysis; J. Hydrol. Eng. 12(4) 394-403.

Reichstein M, Tenhunen J D and Roupsard $\mathrm{O}$ et al. 2002 Severe drought effects on ecosystem $\mathrm{CO}_{2}$ fluxes at three Mediterranean evergreen sites: Revision of current hypotheses; Global Change Biol. 8 999-1017.

Reihan A, Kriauciuniene J and Meilutyte-Barauskiene D et al. 2012 Temporal variation of spring flood in rivers of the Baltic States; Hydrol. Res. 43 301-314.

Santos J F, Pulido-Calvo I and Portela M M 2010 Spatial and temporal variability of droughts in Portugal; Water Resour. Res. 46 742-750.

Serfling R and Xiao P 2007 A contribution to multivariate L-moments: L-comoment matrices; J. Multivariate Anal. 98(9) 1765-1781.

Serinaldi F, Bonaccorso B and Cancelliere A et al. 2009 Probabilistic characterization of drought properties through copulas; Phys. Chem. Earth Parts $a / b / c$ 34(10) 596605.

Shahid S 2008 Spatial and temporal characteristics of droughts in the western part of Bangladesh; Hydrol. Process. 22 2235-2247.

She D X, Xia J and Zhang D 2014 Regional extreme-dry-spell frequency analysis using the L-moments method in the middle reaches of the Yellow River Basin, China; Hydrol. Process. 28 4694-4707.

She D, Mishra A K and Xia J et al. 2016a Wet and dry spell analysis using copulas; Int. J. Climatol. 36(1) 476-491. 
She D, Xia J and Zhang Y et al. 2016b Regional frequency analysis of extreme dry spells during rainy season in the Wei River Basin, China; Adv. Meteorol., doi: 10.1155/ 2016/6427568.

Sklar A 1973 Random variables, joint distributions, and copulas; Kybernetica 9 449-460.

Su W, Zhang X and Wang Z et al. 2011 Analyzing disasterforming environments and the spatial distribution of flood disasters and snow disasters that occurred in China from 1949 to 2000; Math. Comput. Model. 54(3-4) 1069-1078.

Vicente-Serrano S M, López-Moreno J I and Beguería S 2014 Accurate computation of a streamflow drought index; $J$. Hydrol. Eng. 17(2) 318-332.

Whitworth K L, Baldwin D S and Kerr J L 2012 Drought, floods and water quality: Drivers of a severe hypoxic blackwater event in a major river system (the southern Murray-Darling Basin, Australia); J. Hydrol. s 450-451 190-198.

Wu S, Zhang X and She D 2017 Joint occurrence of water quality indexes in relation to river streamflow in the heavily polluted Huai River Basin, China; Water Sci. Tech-W Sup., doi: 10.2166/ws.2017.046.

Wu Z, Li J and He J et al. 2006 Occurrence of droughts and floods during the normal summer monsoons in the midand lower reaches of the Yangtze River; Geophys. Res. Lett. 33(5) 151-162.

Corresponding editor: Subimal GHosh
Yang Z Y, Yuan Z and Fang H Y et al. 2013 Study on the characteristic of multiply events of drought and flood probability in Luanhe River Basin based on copula; $J$. Hydraul. Eng . 44 556-526.

Ye J, He Y and Pappenberger F et al. 2014 Evaluation of ECMWF medium-range ensemble forecasts of precipitation for river basins; Quart. J. Roy. Meteorol. Soc. 140(682) 1615-1628.

Zeng N, Qian H and Roedenbeck C et al. 2005 Impact of 1998-2002 mid-latitude drought and warming on terrestrial ecosystem and the global carbon cycle; Geophys. Res. Lett. 32 45-81.

Zhang S F 2008 Historic droughts of china 1949-2000; Hohai University Press, Nanjing (in Chinese).

Zhang Q, Xiao M and Singh V P et al. 2012 Regionalization and spatial changing properties of droughts across the Pearl River basin, China; J. Hydrol. 472-473(24) 355-366.

Zhang D, Fan L U and Yan D et al. 2014 Spatio-temporal analysis of droughts and the characteristic of continuous seasonal droughts probability in Yunnan province; J. Basic Sci. Eng. 22 705-717 (in Chinese).

Zhang Q, Qi T and Singh V P et al. 2015 Regional frequency analysis of droughts in China: A multivariate perspective; Water Resour. Manag. 29(6) 1767-1787. 